
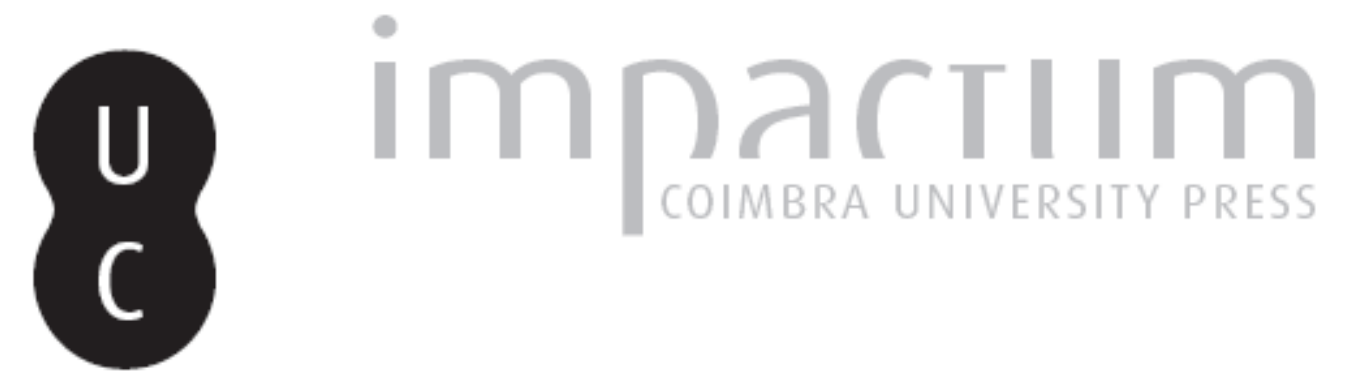

Presença da poesia italiana em Portugal nos últimos 30 anos (1980-2010)

Autor(es): $\quad$ Miraglia, Gianluca

Publicado por: Imprensa da Universidade de Coimbra

URL persistente:

URI:http://hdl.handle.net/10316.2/42495

DOI:

DOl:https://doi.org/10.14195/0870-8584_7_2

Accessed : $\quad$ 26-Apr-2023 09:51:37

A navegação consulta e descarregamento dos títulos inseridos nas Bibliotecas Digitais UC Digitalis, UC Pombalina e UC Impactum, pressupõem a aceitação plena e sem reservas dos Termos e Condições de Uso destas Bibliotecas Digitais, disponíveis em https://digitalis.uc.pt/pt-pt/termos.

Conforme exposto nos referidos Termos e Condições de Uso, o descarregamento de títulos de acesso restrito requer uma licença válida de autorização devendo o utilizador aceder ao(s) documento(s) a partir de um endereço de IP da instituição detentora da supramencionada licença.

Ao utilizador é apenas permitido o descarregamento para uso pessoal, pelo que o emprego do(s) título(s) descarregado(s) para outro fim, designadamente comercial, carece de autorização do respetivo autor ou editor da obra.

Na medida em que todas as obras da UC Digitalis se encontram protegidas pelo Código do Direito de Autor e Direitos Conexos e demais legislação aplicável, toda a cópia, parcial ou total, deste documento, nos casos em que é legalmente admitida, deverá conter ou fazer-se acompanhar por este aviso. 


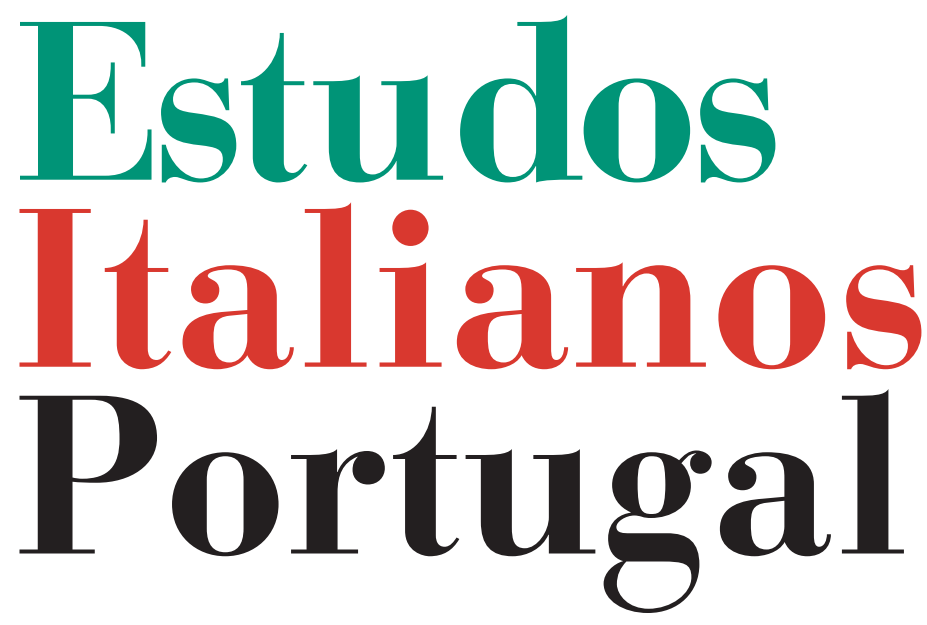

Instituto

Italiano

de Cultura

de Lisboa

Nova Série

$\mathbf{N}^{\mathbf{0}} 7$

2012 


\title{
PRESENCA DA POESIA ITALIANA EM PORTUGAL NOS ÚLTIMOS 30 ANOS (1980-2010)
}

\author{
Gianluca Miraglia $\star$
}

Verificar a dimensáo da presença da poesia italiana no panorama editorial português das últimas três décadas, de 1980 a 2010 e, ao mesmo tempo, esboçar uma espécie de roteiro dos títulos disponíveis, em livrarias ou bibliotecas, mercê de um breve comentário que sublinha os aspectos salientes de cada um deles, e cuja leitura possa ser vantajosa para quem ainda não os leu, é o objectivo deste artigo. Foram tomadas em consideraçáo unicamente as traduçóes publicadas em volume, seja em forma integral seja como selecção antológica. Privilegiando os livros bilíngues, que constituem desde há vários anos o paradigma da correcta edição da poesia estrangeira, assinalei, porém, em nota, outras traduçôes que viram à luz em revistas ou em outro tipo de publicação, de forma que estas páginas possam igualmente servir de eventual ponto de partida para um estudo mais aprofundado e completo da recepçáo da poesia italiana moderna e contemporânea em Portugal, que certamente será levado a cabo um dia.

\footnotetext{
* Doutorado pela Universidade de Bolonha e investigador do Centro de Tradiçóes Populares Portuguesas da Universidade Clássica de Lisboa. Preparou uma edição dos Contos de A. do Carvalhal (Assírio \& Alvim, 2005) e, em colaboração com M. Sacco, organizou, prefaciou e traduziu a antologia de narrativa breve L'anima navigante: racconti dal Portogallo (Besa, 2006).
} 
Começamos, então, pela análise da década de 80 , período em que registamos a existência de duas publicaçóes. A primeira, da Fenda ediçóes, é uma pequena antologia de Salvatore Quasimodo, uma plaquette bilíngue, com o título de $E$ de súbito é noite ${ }^{1}$. A tiragem, deveras limitada, apenas 249 exemplares, indicia que o seu papel na divulgação dum poeta considerado na nota introdutiva "injustamente ignorado em Portugal", deve ter sido diminuto, mas há dois aspectos da plaquette que merecem ser salientados. Em primeiro lugar a qualidade da tradução, que se revela particularmente atenta na busca de reproduzir o andamento rítmico dos originais e que procura encontrar equivalências semânticas capazes de transmitir na versão portuguesa aquela poética da palavra que marca a escrita de Salvatore Quasimodo. Em segundo lugar, apesar de a antologia coligir apenas oito poemas, notase a preocupação, por parte de quem a organizou, Manuel Simôes, de dar uma imagem o mais abrangente possível do poeta distinguido com o prémio Nobel em 1957, incluindo textos pertencentes quer à primeira fase da sua produçáo poética, quer à mais tardia.

A segunda publicação, vinda à luz nos anos 80 , é um pequeno livro consagrado a Giuseppe Ungaretti, com o título Vida de um Homem (escolha poética), que integra a colecção "cão vagabundo" da Editora Hiena ${ }^{2}$. Organizada e traduzida por Luís Pignatelli, apresenta um tipo de tradução que assenta essencialmente na conversão literal dos textos originais, e na selecção privilegia os poemas mais antigos de Ungaretti, excluindo, porém, algumas das composições mais célebres que remontam ao período da Grande Guerra. Talvez a razão duma escolha tão peculiar possa ser imputada não só ao gosto pessoal do tradutor, mas também ao propósito de marcar uma vincada diferença em relação a outra antologia editada

\footnotetext{
${ }^{1}$ S. Quasimodo, E de súbito é noite, Fenda Edições, Coimbra, 1981.

${ }^{2}$ G.Ungaretti, Vida de um Homem (escolha poética), Editora Hiena, 1987.
} 
nos anos $70^{3}$. Com efeito, embora possa parecer incrível, não há sequer um poema comum aos dois volumes.

Passando aos anos 90, também para este período registamos apenas dois volumes de poesia italiana, ambos não bilingues ${ }^{4}$. Editados no ano de 1993, resultam da mesma experiência, ou seja um dos seminários de tradução colectiva que teve lugar no âmbito do programa Poesia Viva em Mateus, mais precisamente o que se realizou no mês de Março de 1992 e no qual participaram os seguintes escritores: Rosa Alice Branco, Nuno Júdice, Adília Lopes, Maria Carlos Loureiro, Gaëtan Martim de Oliveira, António Osório, Laureano Silveira e Pedro Tamen.

O volume Memória, que recolhe poemas escolhidos de cinco livros de Franco Loi (Stròlegh, Teater, L'Aria, Liber, Memoria), tem revisão e apresentação de António Osório. $\mathrm{Na}$ nota introdutiva vem explicado o processo que foi seguido para a tradução da poesia de Loi, originariamente escrita em dialecto milanês; é um processo que exige um breve comentário após a sua transcrição:

Se traduzir nunca é fácil, traduzir Franco Loi é bem difícil. Inclusive dispondo da sua colaboração (que se revelou aliás muito útil), traduzindo ele também, o que escrevera em "dialecto" milanês para italiano. Era a única forma pela qual podia ser traduzido neste encontro de Mateus para a nossa língua: nenhum dos participantes conhecia esse dialecto. $^{5}$

O facto de a tradução ter sido feita a partir de outra língua, o italiano, implica uma sobrevalorização do plano semântico

${ }^{3}$ Refiro-me a um dos "cadernos de poesia", da Dom Quixote, nomeadamente o número 17, com o título Sentimento do Tempo, publicado em 1971, sendo o tradutor Orlando de Carvalho.

${ }^{4}$ Franco Loi, Memória, Lisboa, Quetzal, 1993; Valerio Magrelli, A espinha do P., Lisboa, Quetzal, 1993.

${ }^{5}$ Ib., p. 7. 
em detrimento do plano do significante, sendo que este último, como é notório, marca a especificidade da linguagem poética e do texto lírico; não é o caso de relembrar aqui fenómenos inerentes à poesia, como, por exemplo, a "autonomia do significante", mas parece-me que julgar que o código fónico-rítmico pode ser algo de prescindível, na prática da tradução, remete-nos para para uma obsoleta distinção entre res e verba que confina estas últimas ao simples papel de ornatus. Para além disso, há o risco de transmitir ao leitor português a ideia que, afinal, Franco Loi podia perfeitamente ter escrito os seus poemas em língua italiana, sem que disso resultasse grande diferença.

A antologia dedicada a Valerio Magrelli, A espinha de P., cujo breve mas elucidativo prefácio é assinado por Maria Carlos Loureiro, recolhe poemas escolhidos dos três livros que o poeta publicara até à data (Ora serrata retinae, 1980; Nature e Venature, 1987; Esercizi di tipologia, 1992), e permitem ao leitor português ter uma visão suficientemente abrangente da produção poética de Magrelli, através duma tradução particularmente cuidada. Merecem ser assinalados dois textos muito sugestivos que apresentam uma reflexão sobre a prática da tradução - aliás, Magrelli é um exímio tradutor de poesia francesa, "O embalador" ("Limballatore") e "Contra a Tradução", versão portuguesa da versão italiana, feita por Magrelli, dos primeiros versos de uma curiosa composiçáo em língua francesa do século XVII, de autoria de Guillame Colletet, cujo título significativo é Discours contre la Traduction.

Chegamos agora ao princípio do novo milénio, no qual se assiste em Portugal ao despertar de um renovado interesse pela poesia italiana moderna e contemporânea, ao qual se alia a divulgação de obras maiores da tradição lírica italiana, que constituem de resto marcos fundamentais da literatura europeia, como é o caso da Divina Commedia de Dante, do Canzoniere de Petrarca, ambos vertidos por Vasco Graça 
Moura, e de o Orlando Furioso de Ariosto, traduzido por Margarida Periquito ${ }^{6}$.

Um papel de primeiro plano, nessa actividade editorial, é desempenhado pela Assírio \& Alvim que no breve espaço de oito anos publicou seis volumes, sendo o primeiro, editado em 2002, O Passo do Adeus de Cristina Campo, pseudónimo de Vittoria Guerrini. Não deixa de ser surpreendente, na realidade, que seja este o primeiro livro de poesia italiana a integrar a prestigiosa colecção "Documenta Poética", mas, como teremos ocasiáo de verificar a seguir, por vezes as editoras parecem ser mais sensíveis a personalidades singulares, no plano literário e biográfico, independentemente da sua efectiva relevância no cânone da poesia italiana do século XX.

O volume, que recolhe a breve produção poética da autora, ou seja o livro Il Passo dell'addio, mais o Quadernetto e as Poesie sparse, contém um prefácio assinado por José Tolentino de Mendonça ao qual se deve também a tradução dos poemas. Se, numa apreciação global, pode dizer-se que o livro cumpre eficazmente a sua função de levar junto do público português a poesia de Cristina Campo, também é verdade que a presença nas versóes de alguns erros graves, resultado da incompreensão de palavras ou expressóes do original, suscita perplexidades, dado que uma revisão literária cuidadosa, como é de resto apanágio da editora Assírio, deveria tê-los emendado. Veja-se, como exemplo, a tradução dos seguintes versos que acaba inevitavelmente por afectar toda a composição em que se inserem:

"Muta affilavo il cuore / al taglio di impensabili aquiloni" = "Emudecida, afiava o coração / na navalha das águias impensáveis" (os "aquiloni” são na realidade "papagaios de papel");

${ }^{6}$ Divina Comédia, Lisboa, Bertrand, 1996; As rimas de Petrarca, Lisboa, Bertrand, 2003; O Orlando Furioso, Lisboa, Cavalo de Ferro, 2007; Vasco Graça Moura traduziu de Petrarca também os Trionfi (Os Triunfos de Petrarca, Lisboa, Bertrand, 2004).

${ }^{7}$ O passo do Adeus, p. 23. 
"mani vive, cercandomi..." = "mãos vivas, cercando-me" ("cercare" significa "buscar");

“... e divezzare / l'attesa dalla sua consolazione, / seno antico che non ha più latte" = "... e divisar a espera da sua consolaçáo, / seio antigo que perdeu o leite" ("divezzare" significa "desmamar");

"col mendicante livido, acquattato" = "com o mendico lívido, banhado de chuva"10 ("acquattato" significa "escondido, agachado").

"t'ho barattato, amore, con parole" = "desbaratei-te, amor, com palavras"; ("barattare" significa "trocar").

Ainda no ano de 2002, a Assírio \& Alvim edita o volume $\mathrm{O} \mathrm{Mel}$, de autoria de Tonino Guerra. Trata-se duma obra integral e não de uma escolha antológica, um poema em 36 breves cantos, escritos em dialecto romagnolo, cuja tradução levantou, como no caso da poesia de Franco Loi, um problema que foi resolvido com a ajuda do autor:

O próprio Tonino Guerra propôs que se elaborasse a tradução portuguesa a partir do romagnolo, emprestando para isso memórias, propostas, esclarecimentos, correcçóes, tudo o que foi determinante para este projecto. Recordo que o canto Vinte e Quatro, por exemplo, "encomendado" por Fellini para o filme Casanova, valeu muitos telefonemas para Portugal na obstinada busca de uma palavra, "quase dialectal" que adensasse o carácter misterioso do poema. Dos quatro ou cinco termos apresentados, quis ser Tonino a escolher.

O que chama a atenção no trecho citado é a referência ao, nas palavras do prefaciador, 'carácter misterioso' do canto Vinte e Quatro, e a descrição minuciosa da árdua procura de um termo equivalente em português para uma palavra italiana, que é, aliás, a que mais recorre no Canto, ou seja "figa". Parece evidente a preocupação, por parte do tradutor,
${ }^{8} I b .$, p. 25.
${ }^{9} I b .$, p. 29.
${ }^{10} \mathrm{Ib}$.
${ }^{11}$ Ib. p. 35 . 
em atenuar ou disfarçar o ditado original através de um eufemismo. A troca de impressóes com o autor teve como resultado a imposiçáa da vontade deste último, de modo que, neste caso específico, o "pudor" do tradutor não desvirtuou a linguagem clara, transparente e inequívoca do original. Não aconteceu, porém, o mesmo, em relação a outro poema de Tonino Guerra, incluído no volume Histórias para uma noite de calmaria $^{12}$, editado pela Assírio sempre no ano de 2002, de que transcrevo os primeiros versos:

Sentado diante do telefone

Com o pássaro na mão

Estive hoje todo o dia.

Ninguém me telefonou

Nem sequer prostitutas.

Apenas um desconhecido

Desligou ofendido

Quando the revelei

Que tinha o pássaro na mão.

Em jeito de comentário vale a pena notar que, se na maior parte dos casos o recurso ao eufemismo visa atenuar a obscenidade do original, sem que disso todavia resulte uma profunda alteração do seu sentido, aqui a tradução transforma o que não passa da descrição transparente duma cena banal e sórdida num poema susceptível de interpretaçóes várias, quer sejam elas literais ou metafóricas.

${ }^{12} \mathrm{O}$ título original do livro é Il Polverone. Storie per una notte quieta. A alteração do título, na edição portuguesa, com o desaparecimento da palavra "polverone", talvez se explique pelo facto de o tradutor ter traduzido o título do texto n. ${ }^{\circ}$ 4, "Il Polverone", com "nuvem de pó", e, no próprio texto, ter feito corresponder a "un vento che si chiama il Polverone", o sintagma "um vento, uma espécie de nuvem de pó”. Tendo em conta a relevância do termo para a leitura e interpretação de todo o volume, teria sido porventura melhor procurar uma solução mais adequada e que não obrigasse a uma modificação tão drástica do próprio título da obra. 
Sempre integrada na colecção 'Documenta Poética', no ano de 2003, vem à luz uma antologia da poesia de Sandro Penna ${ }^{13}$. O prefácio é de Natalia Ginzburg enquanto tradução e escolha de textos são de responsabilidade de Maria Jorge Villar Figueiredo, que, sendo conhecida sobretudo como uma brilhante tradutora de narrativa francesa, tinha no seu curriculum também versôes de romancistas italianos, como, por exemplo, Susanna Tamaro e Andrea Camilleri. O extremo cuidado em restituir na sua integridade o plano semântico dos originais é, talvez, reflexo dum seu maior pendor pela tradução de textos narrativos, mas por vezes está na origem da escrita de linhas, na versão portuguesa, que dificilmente podem ser aceites como versos.

Abrindo um breve parêntesis, convém esclarecer que, desde há muito, a alternativa, na tradução poética, já não é entre uma tradução que espelhe na língua de chegada a estrutura métrica do original, e porventura também as rimas, e uma tradução literal, que se focaliza no conteúdo semântico, subalternizando o plano do significante, o que até certa altura equivalia substancialmente a uma versão em prosa, ou interlinear. A afirmação do verso livre abriu novos caminhos não só à criação poética mas também à tradução, oferecendo ao tradutor um maior leque de possibilidades para recriar na sua língua o texto lírico original. Acontece, porém, amiúde que as traduçóes tenham do texto lírico só uma característica, isto é a disposição gráfica, e se as lermos, sem pensar que são traduçóes, temos enormes dificuldades em descortinar um ritmo, uma versificação, enfim algo que lhes dê uma coerência textual. Fica-nos, em suma, a impressão que o texto da tradução não se apresenta, e afirma, como autosuficiente, mas remete constantemente para o original que o justifica na sua idiossincrasia.

\footnotetext{
${ }^{13}$ Sandro Penna, No brando rumor da vida, Lisboa, Assírio \& Alvim, 2003.
} 
A escolha antológica é outro aspecto que merece um comentário. Quem lê o volume tem alguma dificuldade em reconhecer o autor que escreveu o verso "Sempre fanciulli nelle mie poesie!", e cuja popularidade assenta em grande parte no facto de ter glosado persistentemente uma temática específica. Se lermos, por exemplo, os poemas traduzidos por Gastão Cruz, na revista Relâmpago ${ }^{14}$, advertimos de imediato uma diferença notável; com isso não se quer negar a possibilidade de existirem várias opçóes legítimas numa escolha antológica, mas se pensarmos que a finalidade principal dum volume desse género é justamente o de dar a conhecer ao leitor português a poesia dum autor estrangeiro nas suas características mais marcantes, é claro que se impunha uma maior ponderação na escolha.

O volume Poesia de Pasolini, publicado pela Assírio \& Alvim em 2005, com selecção e tradução de Maria Jorge Villar Figueiredo, revela-se mais equilibrado nos critérios antológicos e náo há dúvida que transmite ao leitor português uma imagem equivalente na substância à que se difundiu na cultura italiana. Em relação à tradução, vale o que se disse anteriormente, a conversão literal é segura, mas alguns traços peculiares da versificação de Pasolini, é o caso, por exemplo da terza rima, diluem-se na versão. O defeito maior, porém, que se pode imputar a esta antologia, pode não ter sido responsabilidade do tradutor, mas sim ser consequência de uma opçáo editorial. Provavelmente para não tornar o livro ainda mais volumoso do que é, sobrecarregando-o com uma série de notas, a edição portuguesa limita-se a reproduzir o aparato da edição italiana que consiste nas anotaçóes acrescentadas pelo próprio autor. A verdade é que se, para um leitor italiano, essas notas podem ser suficientemente esclarecedoras, e mesmo assim é provável que um leitor jovem precise de explicaçóes adicionais, para o público português são mani-

\footnotetext{
${ }^{14}$ Cf. n. 11, Outubro de 2002, pp. 191-205.
} 
festamente escassas. Com efeito, ao longo de vários poemas surgem disseminadas referências a factos, acontecimentos, personalidades do mundo político e cultural, e a situaçóes específicas da sociedade italiana dos anos 50 e 60, cujo conhecimento é fundamental não só para uma correcta interpretação dos textos mas até para a sua compreensão no plano estritamente literal ${ }^{15}$.

Em 2004, a editora Cotovia publica o volume Terra Santa, versão integral dum livro de Alda Merini. A tradução, muito atenta à letra, por vezes visa manter o código métrico do original, em particular quando procura reproduzir os versos decassilábicos que constituem um traço marcante da linguagem poética de Alda Merini. No prefácio, assinado pela tradutora, Clara Rowland, justifica-se a opção editorial, informando o público português que, no seu país de origem, a personalidade artística e biográfica da escritora náo se restringe à que emerge da leitura desta única obra:

A imagem de Alda Merini que aqui se apresenta não é a mesma que se criou em Itália desde o início dos anos noventa e que se encontra, hoje, entrando numa livraria italiana e observando a forma como o seu nome aparece em mostruários e escaparates. Também não se trata do retrato que dela fizeram os que a conheceram na adolescência. A Alda Merini que aqui se apresenta reside unicamente neste território indefinido que vai ganhando forma ao longo dos quarenta poemas de A Terra Santa (1984), palco de projecçôes e de sobreposiçóes, condensação máxima das várias metáforas sobrepostas à palavra manicómio, que é também teatro de um mundo menor. ${ }^{16}$

${ }^{15}$ A tradutora entendeu correctamente a quase totalidade das referências, mas num caso tomou dois nomes próprios, de escritores, por substantivos, traduzindo '(Soldati, Piovene)' com (“Soldados, Abades”).

${ }^{16}$ P. 9. Na revista Relâmpago, 17, Outubro de 2005, pp. 101-121, foram apresentados vários poemas de Alda Merini traduzidos por Marco Bruno, com revisão de António Osório. 
Em 2006, sempre na colecção "Documenta Poética" da Assírio \& Alvim, sai o volume Poesia de Eugenio Montale, uma ampla antologia organizada por José Manuel de Vasconcelos em que ressalta o profundo empenho em tornar possível um encontro profícuo entre o poeta italiano e um leitor pertencente a outra cultura literária através duma mediação que visa, antes de mais, encurtar a distância que os separa, mercê de um prefácio amplo e exaustivo, e de anotaçóes oportunas e claras que permitem um entendimento mais adequado dos poemas e por fim, o que é ainda mais relevante, através duma tradução cujo objectivo é o de alcançar em língua portuguesa um efeito equivalente ao que sentem os leitores italianos perante os originais.

Obviamente só uma frequentaçáo longa e profunda da obra de Montale torna possível a concretizaçáo desse objectivo que se manifesta nas opçóes que o tradutor toma, com base numa compreensão exacta do que constitui o essencial da poesia de Montale, para determinar o que deverá ser impreterivelmente transposto e o que poderá perder-se na passagem de uma para outra língua. Elucidativo, nesse sentido, é o breve texto "Traduzir Montale" que leva o leitor ao interior da oficina do tradutor:

... procurei uma solução de compromisso que preservasse o sentido acima de tudo, mantendo a rima na tradução sempre que tal manutenção não violentasse o original, e abandonando-a, quando ela implicasse reescrever à minha maneira os poemas, fazendo versôes em lugar de traduções ... quando não foi possível a manutenção integral da rima, procurei através de rimas alternativas, em outros momentos do poema, ou da conjugação de outros valores rítmicos dar à tradução a unidade de que a rima abandonada a poderia ter privado [...]. O ritmo dos poemas em italiano é muito peculiar [...] fiz um esforço, também dentro do possível, para não me distanciar muito dos valores métricos e rítmicos [...] procurei sobretudo fazer com que o poema soasse ritmicamente a um português, de forma semelhante àquela que uns ouvidos italianos escutam, quer na suavidade, quer na aspereza. 
O último livro publicado no interior do arco temporal que fixámos para este roteiro é Poesia, de Umberto Saba, também este incluído na colecção "Documenta Poética" e com "selecção, tradução, introdução e notas" de José Manuel de Vasconcelos e sobre o qual mais náo poderemos dizer senão repetir o que foi dito acerca do volume dedicado à poesia de Eugenio Montale ${ }^{17}$.

Em jeito de conclusão, perante o quadro traçado de trinta anos de divulgação da poesia italiana moderna e contemporânea em Portugal, impóem-se algumas consideraçôes. Em primeiro lugar deve salientar-se o persistir da ausência de uma antologia geral da poesia italiana do século XX, que permitiria ao leitor português ter uma visão de conjunto do que foi a produção poética italiana ao longo do século passado, evidenciando correntes e geraçóes literárias.

Em segundo lugar, o elenco dos volumes publicados ao longo das últimas três décadas evidencia que, por vezes, as opçôes editoriais não se baseiam no valor absoluto dos autores propostos, mas privilegiam escritores que, embora apresentem características singulares e possuam uma personalidade artística sem dúvida notável, não ocupam um lugar de primeiro plano no panorama da poesia italiana.

Finalmente, ao considerarmos as geraçóes literárias que se sucedem ao longo do século XX, notámos que, se, para a poesia da primeira metade do século, o leitor português tem agora à sua disposiçấo antologias dos autores maiores (Montale, Saba, e em parte Ungaretti), já para a segunda metade do século dispóe unicamente do volume de poesia de Pasolini, enquanto desconhece poetas fundamentais como, por exemplo, Caproni, Sereni, Zanzotto ou Giudici ${ }^{18}$; enquanto

${ }^{17}$ José Manuel de Vasconcelos traduziu também poemas de: Cristina Babino, Vita di provincia (Vida de provincia), in Foro das Letras, 17/18, Julho de 2009, pp. 59-71; Antonio Catalfamo, Poemas, in Foro das Letras, 19/20, Dezembro de 2010, pp. 168176; Eugenio De Signoribus, Poemas, in Foro das Letras, 21 [no prelo].

${ }^{18}$ Vale a pena notar, todavia, que vários textos de poetas italianos do século XX 
a poesia mais recente, se excluirmos o caso de Valerio Magrelli, permanece substancialmente ignota.

podem ser lidos nas antologias organizadas por J. de Sena, A. Herculano de Carvalho, Pedro da Silveira e David Mourão Ferreira: em Poesia do século XX (Porto, Asa, 2. a ed., 2002), há poemas de Pascoli, D’Annunzio, Ada Negri, Saba, Campana, Palazzeschi, Corazzini, Cardarelli, Ungaretti, Montale, Quasimodo, Penna, Pavese, Fortini, Elena Bono, Pasolini, Cattaneo; em Oiro de vário tempo e lugar (Porto, Asa, 2. a ed., 2002) encontram-se textos de Corazzini, Govoni, Gozzano, Marinetti, Onofri, Palazzeschi e Pavolini; em Mesa de amigos (Lisboa, Assírio \& Alvim, 2002), há composições de Saba, Palazzeschi, Campana, Valeri, Cardarelli, Sbarbaro, Ungaretti, Montale, Quasimodo, Pavese; por fim, na revista Colóquio-Letras, 165, Setembro-Dezembro de 2003 (“Vozes da poesia europeia III"), encontram-se poemas de D’Annunzio, Saba, Montale, Penna, Caproni. 